\title{
The change of supply chain in the transformation of traditional retail enterprises to new retail enterprises: A case study of Chinese RT-Mart
}

\author{
Qunzhi Zhou ${ }^{1,{ }^{*}}{ }^{\dagger}$, Chuang Wang ${ }^{2, \dagger}$ and Yihan Wang ${ }^{3, \dagger}$ \\ ${ }^{1}$ School of Transportation and Logistics Engineering, Wuhan University of Technology, China \\ ²ogistics College, Beijing Normal University, Zhuhai, China \\ 3 Jining Confucius International School, Shandong, China \\ ${ }^{*}$ Corresponding author: guanghua.ren@gecacademy.cn \\ tThese authors contributed equally
}

\begin{abstract}
With the development of e-commerce industry and the arrival of the new retail era, traditional retail enterprises have to step into the field of e-commerce, change the sales model and redesign the complete new supply chain. This paper mainly introduces the market competition environment and internal reform pressure faced by traditional retail enterprises, taking Ruentex-Mart as an example, analyzes the advantages and problems of supply chain reform, and puts forward corresponding solutions for other traditional retail enterprises.
\end{abstract}

Keywords: Supply Chain Management, Retail Business, Delivery Service, Big Data

\section{Introduction}

\subsection{The emergence of new retail has revolutionized supply chains}

Supply chain is everywhere in our life, and now we walk on the street, visitors are greeted behind each store, one is complex and complete supply chain, convenient and quick to ensure our daily life, a biscuit before came to our eyes, may need to go through hundreds way across the mountains, to perfectly on shelves. In 2016, Jack Ma, with infinite imagination of the e-commerce industry, made it clear at the "Cloud Conference" that pure e-commerce would soon come to an end, and there would be no e-commerce in the next 20 years, only "new retail". The emergence of new retail marks the traditional industry and electricity industry upgrade wave will appear new fusion, rt-mart as traditional retail giant, retail income up to 102.3 billion yuan in 2017 , physical retailers in mainland China in four hundred [1].After realized that must be combined online, traditional retail companies, led by rt-mart, began to transition to a new retail, combined to create online new retail supply chain in order to meet The Times.

\subsection{The problems faced by the transformation of traditional retail enterprises}

But in the field of never to set foot in the transformation of traditional industry will undoubtedly face inevitable challenges, how to get the original from the supply to the retail supply chain transformation for a new type of supply chain from the supply to the customers, new and perfect from retailers to customers at the end of the supply chain, become the first in the transformation of the traditional retail enterprise big problem. Traditional retailers only need to maximize the production and supply of products, but how to use the Internet to integrate customer demand information into the whole link of the supply chain and provide the most appropriate goods to the most appropriate customers has become the second major problem of supply chain transformation. How to solve these two problems has become the main difficulty of traditional retail enterprise supply chain transformation. 


\subsection{Research objectives}

When RT-Mart independently attempted to stride forward to the e-commerce industry of "Internet plus", it independently established the e-commerce website Feiniu.com to build a $3 \mathrm{~km}$ one-hour business area with stores as the front position. However, since 2016, the revenue of single stores has declined, and Feiniu.com has been in a loss state.As shown in Table 1,although there were increases in all numbers, none were significant. Hema, also a retail enterprise, officially opened its first offline store in Shanghai in 2016 and has grown rapidly since then. As of April 2021, Hema has 152 stores nationwide, mainly distributed in the first and second tier cities such as Beijing and Shanghai.It can be seen that when traditional retail enterprises make bold attempts to reform the structure of supply chain, they need to have a more comprehensive understanding of the e-commerce industry in the process of integrating into e-commerce, summarize the new profit points that can be used to create, and avoid the disadvantages caused by incomplete integration, so as to achieve maximum economic benefits.Previous research projects focused on the necessity of transformation, but did not focus on the conflicts and deficiencies that are prone to occur in this process, which is the in-depth goal of our research.

Table.1. RT-Mart Annual Report

\begin{tabular}{|c|c|c|c|}
\hline & $2016(\mathrm{RMB})$ & $2017(\mathrm{RMB})$ & Amplitude of Vibration \\
\hline Income & $100,441 \mathrm{M}$ & $102,320 \mathrm{M}$ & $1.9 \%$ \\
\hline Gross Margin & $23981 \mathrm{M}$ & $24674 \mathrm{M}$ & $2.9 \%$ \\
\hline Operating Profit & $3936 \mathrm{M}$ & $4487 \mathrm{M}$ & $14 \%$ \\
\hline $\begin{array}{c}\text { Profits attributable to equity shareholders } \\
\text { of the company }\end{array}$ & $2571 \mathrm{M}$ & $2793 \mathrm{M}$ & $8.6 \%$ \\
\hline EPS & 0.27 & 0.29 & \\
\hline
\end{tabular}

\section{Market analysis and new supply chain advantages}

\subsection{Market background}

With the rapid development of global economy, foreign retail convenience store in home, for example, wal-mart, amazon, metro and other foreign retail enterprises, due to the supermarket on the international reputation and public praise, makes the chain rapid distribution throughout the country, occupying most of the market in our country, the impact of local enterprises in China are greatly.

\subsubsection{Wal-Mart's business model}

Wal-Mart, the world's largest retailer, was an early entrant into The Chinese market.Wal-mart's business format in China is perfect, including advanced retail formats such as membership store and $\mathrm{O} 2 \mathrm{O}$ model. In addition, Wal-Mart has the largest number of stores and employs a large number of Chinese employees. There are many successes and experiences worth learning in market operation management and supply chain management strategies [2].

(1) Low prices every day: Wal-mart keeps reducing prices through its huge sales volume to save money from various aspects such as purchasing channels, publicity costs, goods transportation and administrative expenses. Wal-mart's approach is to separate procurement from operations, that is, to buy directly from the factory and distribute according to the needs of each store. The cost that the manufacturer needs to pay is also reflected in the form of commodity, reducing the commodity value of the manufacturer.

(2) Member store: Sam's store, a member store of Wal-Mart, is targeted at middle and high-end user groups. It charges 150 yuan per year to provide a small number of high-quality global selected goods and abundant tasting services, and its price is about $8 \%$ lower than that of other stores, 
attracting a large number of customers.Sam's is arguably wal-mart's most profitable store, selling as much as five or six wal-mart hypermarkets [3].

(3) Online sales: Wal-mart provides online sales service, establishes its own online sales website and provides door-to-door delivery service, which provides consumers with a more convenient way of consumption and provides sales channels for many e-commerce enterprises.

\subsubsection{Wal-Mart vs. RT-Mart}

Rt-mart pays more attention to fresh products.First of all, RT-Mart's fresh products are all on the first floor, while Wal-Mart's fresh areas are mostly on the second floor. Compared with RT-Mart's tally and replenishment frequency, RT-Mart's fresh products are relatively better, and the out-of-stock rate is lower.Second, the proportion of fresh food is significantly higher than that of Wal-Mart. Rtmart has more varieties of fresh food, which can meet more kinds of customer needs.Third, the fresh price is generally $10 \% \sim 20 \%$ lower than that of similar supermarkets. In order to ensure low price, RT-Mart makes great efforts in source direct procurement. The direct procurement mode of black pork, peach, lychee and other fresh products has become a classic case, sticking to the development strategy and avoiding cannibalization.

Wal-Mart's O2O model is more mature. At the end of 2016, Wal-Mart increased its stake in Jingdong Mall.com by another 5\% to $12.1 \%$, becoming the third largest shareholder of JD.com. Walmart's Sam's Club, the official global flagship store and the official global purchase flagship store have also entered jd.Consumers can purchase products from The Walmart channel on JD Mall, and also enjoy the delivery service of JD.In contrast, The website founded by RT-Mart still lacks reliable logistics partners, and most domestic logistics companies are unable to solve RT-Mart's "last mile" problem, which makes most customers dissatisfied with RT-Mart's delivery services.

Rt-mart uses the Warehouse Management System (WMS) to manage the goods stored in the warehouse, including counting, checking and shipping.WMS not only ensures the smooth flow of goods and saves distribution costs, but also ensures the circulation of goods between suppliers, RTMart and consumers.Therefore, the effective implementation of WMS can enhance the competitiveness of RT-MART, improve the efficiency of inventory management, and improve its resource utilization.However, Wal-Mart adopts the suitable inventory management mode (JITIM), whose core idea is to take the market as the center and produce continuously according to the market demand.It reduces unnecessary inventory, reduces costs, shortens inventory cycles, keeps money flowing, and keeps products fresh and diverse.

According to the latest "2018.2023 Chinese supermarket Industry Business Model and Investment Strategy Planning Analysis Report" released by The Qianzhan Industry Research Institute, in 2016, the sales scale of top 100 supermarket enterprises reached 1.09 trillion yuan, an increase of more than 3 percentage points compared with 2015: the number of offline physical stores also e xceeded 100,000 .It can be seen that China's retail industry needs to carry out fundamental reform in the structure and strategy of supply chain in the face of huge double competition pressure at home and abroad. According to the report of China National Business Information Center,Mature retail enterprises have established excellent new supply chains, have mature models in inventory, logistics and other fields, and successfully integrated into the e-commerce market.Their online physical retail sales are also increasing. As shown in figure 1, the monthly retail sales have increased gradually in the past two years. Traditional retail enterprises need to maintain their own characteristic operation strategies while speeding up the speed of supply chain innovation. 


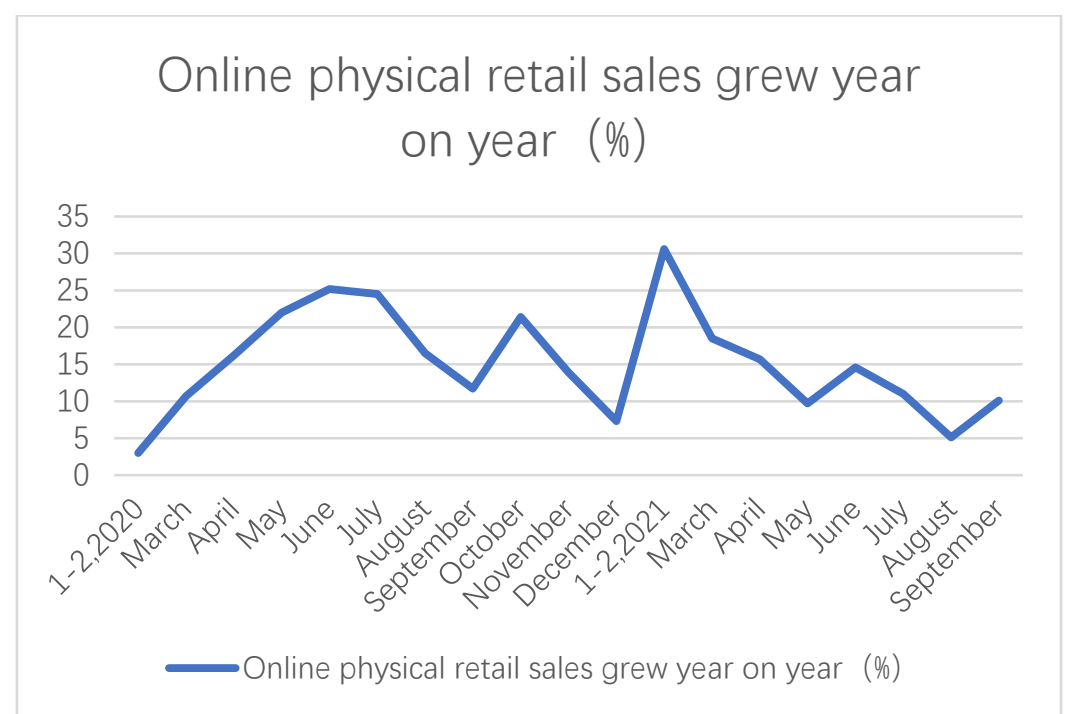

Figure 1. RT-Mart monthly online sales growth rate

\subsection{The inevitable emergence of the supply chain of new retail enterprises and market changes}

New retail industry is a new business concept, since 2016, all kinds of new retail formats have emerged, new retail enterprise supply chain is gradually replace the traditional retail enterprise supply chain and led the entire retail industry gradually upgrade, new retail model is the trend of The Times, many enterprises in the early new retail soon after was first put forward into a new retail areas, seize the opportunity, a retail giant, so the emergence of new retail enterprise supply chain what reason is caused?According to the survey, we think there are mainly the following reasons.

\subsubsection{The promotion of the status of consumers [3]}

Now in China, no matter in any market, consumers are basically in the dominant position, and consumers' demand and mentality will change with the changes of The Times.Everything a consumer needs can be bought in the market, and then the consumer will compare and choose the cheapest; The best quality or the most convenient to buy, at this time need to change their business model with the needs of consumers, to achieve personalized needs, point-to-point consumption, consumers become the core of the new retail.

\subsubsection{Technological innovation}

With the progress of science and technology in our country, the electricity is now the market is very big, such as Taobao, Jingdong APP, such as shopping provides great convenience for us, don't need to go to the store, sitting at home can buy anything you need, like a physical store to development to online stores the same principle, the generation of new retail business is only as the main stream of the development of science and technology, as well as wisdom logistics, big data, cloud computing and other advanced algorithm model for the generation of new retail laid a good foundation.

\subsubsection{Shortage of passenger flow}

With the rise of e-commerce, offline stores have been greatly impacted, with a sharp decline in customer flow, and the commodity homogeneity in e-commerce platforms is becoming more and more serious. In addition, the flow bonus period with the help of the Internet has already passed, and the pure e-commerce model has reached a bottleneck. Therefore, in order to break through the bottleneck period and increase customer flow, the integration of online flow and offline experience has become an inevitable trend of new retail transformation.

\subsubsection{The impact of COVID-19}

Due to the COVID-19 outbreak that began last year, various provinces and regions have adapted to some new policies, such as home quarantine, closed community management, closure of entertainment venues, shutdown of companies and enterprises, etc.The closure of entertainment 
venues also includes various shopping malls and supermarkets.Consumers can only shop on the Internet, so most stores have established online shops, which can choose goods online and mail them home.Before the epidemic, many offline stores did not set up online stores, and consumers could only consume and buy goods in physical stores.However, due to the impact of the epidemic, these shops have to become a member of the new retail industry, promoting the new retail industry to the network, intelligent direction upgrade.

\subsection{Advantages of supply chain of new retail enterprises}

At the end of 2017, Alibaba invested HK \$22.4 billion in Sun Art retail and reached a new retail strategic cooperation with Sun Art Retail Co., LTD. RT-Mart has achieved great success by using some of Ali's advanced technologies.

\subsubsection{Apply Hema Fresh's business model [5-6]}

After Alibaba entered sun Art, Hema's business model was quickly applied to RT-Mart. Hema Fresh Is the first new retail enterprise created by Ali and also the benchmark work of new retail. Hema is responsible for transforming RT-Mart's digital technology and taking over the delivery task of RTMart. In just one month, the supply chain system between Hema and RT-Mart has been formed. Hema's move, greatly shorten the time from the beginning of the order to distribution.The most critical aspect of Hema's business model is its distributed suspension chain system. The system is mainly used to accept online orders, which are transported from the shelf to the warehouse through the suspension system. Different colored plastic bags are used to distinguish different temperatures, such as red bags for cooked food, green bags for low temperature, and gray bags for normal temperature.Through differentiation, the efficiency of preparing and picking goods is improved, and online orders can be delivered within an hour.

\subsubsection{Use big data to display commodities [7]}

Rt-mart has changed the traditional way of product display and used big data analysis to place the popular products with the best sales volume and the most interest of customers in the most eyecatching position. With the rise of Apps such as Douyin and Xiaohongshu, many online celebrity products have become popular. Rt-mart has also cleverly placed all kinds of online celebrity products everywhere.It can not only benefit consumers to choose favorite goods, but also meet consumers' curiosity to keep up with the trend.Fine-tuning through daily data changes to keep up with the trend of the public.

\subsubsection{Launch smart Shopping area}

Traditional supermarkets can only guarantee the complete range of goods, but they do not attach much importance to the planning of goods. Most of the time, we need to go around the whole supermarket or ask the service staff of the supermarket to find all the goods we want to buy, which is time-consuming and laborious for consumers.In order to improve the shopping experience, RT-Mart has transformed the special areas of some stores. For example, RT-Mart Shanghai Yangpu store launched the "Tmall Smart Mother and Baby Area", which divides products according to specific groups.Through background data analysis, more accurate understanding of consumer demand is conducive to accurate marketing.

\subsubsection{Store digitization and intelligence [8]}

Under the new retail status, with the continuous development of technology, RT-Mart is bound to upgrade its stores.Rt-mart has carried out three major reforms to realize the transformation from offline to online.

(1) Carried out online digital marketing for the store members, and launched its own Wechat public account -- RT-Mart.

(2) RT-Mart joined Alibaba's "Tao Xian Da", mainly for the online marketing of some fresh products. 
(3) RT-Mart's access to the "Taobao Home" system has realized the intelligent digital operation of offline stores.

These newly launched retail operation modes not only provide consumers with a more convenient way to shop, but also stimulate consumers' desire to shop and improve the operation efficiency of stores.

After the in-depth cooperation between RT-Mart and Ali, the order volume of a single store can increase by thousands of orders per day on average, the on-time delivery rate of one-hour is over $99 \%$, and the overall benefit has increased by $15 \%$. The impact of Alibaba's new retail strategy on RT-Mart is obvious.

This also proves that the supply chain of new retail enterprises has a very significant change compared with the supply chain of traditional retail enterprises, which can not only shorten the time spent in each link of the supply chain, reduce the cost, but also increase customer satisfaction.

\section{The new retail model is prone to problems}

\subsection{Supply chain logistics - Distribution service scope is not comprehensive}

Up to January 2020, RT-Mart has successfully opened 416 comprehensive hypermarkets in mainland China. In supply chain inventory, Rt-mart adopts decentralized warehouse storage mode and stores as delivery points, enabling each user to obtain convenient and fast services through online shopping.However, in supply chain distribution,retail enterprises lack the integrity of the national market layout and only provide distribution services in some areas.Rt-mart only distributes in Shanghai, Jiangsu, Zhejiang and Anhui, which is still a long way from establishing a national market layout.The construction of the supply chain in the field of logistics and distribution is incomplete. In the transformation from the traditional retail industry to the new retail industry, it is a process to provide distribution services to each customer from scratch. The development is slow but the demand is high, so it is difficult to provide complete logistics and distribution services across the country quickly.

\subsection{Supply chain distribution service level is difficult to guarantee}

Rt-mart to enter the Chinese mainland since 1997, has been to three or four line city has the growth of the business circle as the goal, and Wal-Mart, Carrefour and other large retail enterprises are completely different, which makes it get sufficient development, have relatively perfect B2B logistics distribution system, but the new retail B2C logistics distribution system requires traditional retail enterprise to the logistics company again cooperation, improve the supply chain."Flying Cattle" in Jiangsu, Zhejiang, Shanghai, Anhui and Cooperation with Huiwen express company, Huiwen is responsible for overall distribution.However, third-party express delivery companies are also subject to relevant restrictions, which makes it difficult for RT-MART to provide the ideal service level and meet the standard of one-hour delivery within three kilometers, thus reducing customer satisfaction.Some enterprises will try to build their own new express delivery system, but the investment cost is huge and the risk is high. It is difficult to ensure that the service can be satisfied while maintaining profits.

\subsection{It is difficult to guarantee the integrity of online sales [9]}

Rt-mart operates its own Wechat public account and accesses Alibaba's "Taoxianda" and "Taobao Home". While making profits on the online platform, RT-Mart also faces difficulties in sales on the online platform. Customers have doubts about the quality of products and the authenticity of product information.In the traditional retail model, customers can directly contact the products and distinguish the advantages and disadvantages of the products to a certain extent. However, on the e-commerce platform, there is a certain error between the actual effect of the products and the expectations of customers, which may lead to the increase of the return rate, the decline of the brand effect of the enterprise, and the damage to the reputation. 


\section{New retail industry optimization plan}

\subsection{Work together to solve the "last mile" problem in terms of logistics}

Rt-mart basically cooperates with a third party by outsourcing the last process of distribution to the third party logistics.In order to ensure a certain level of service, new retail enterprises can sign contracts with logistics companies for strategic cooperation and information sharing to jointly complete the service of home delivery. While ensuring timely information, they urge express companies to complete the service and make profits together.

\subsection{Perfect the layout and form the brand effect in terms of brand}

The Wall Street Journal has reported that Amazon plans to open more than 2,000 physical stores in the United States. E-commerce develops rapidly with advantageous channels, but after a certain stage, it will transform into a docking platform to strengthen the company's brand recognition.For large retail enterprises, during the transformation, they should complete the national network layout as soon as possible, serve multiple regions as much as possible, build brand image, improve the national supply chain, and make the national branches make profits together.For small and mediumsized retail enterprises, we should focus on provincial layout, build first-class retail brands in the province and improve supply chain efficiency at the same time.

\subsection{Provide perfect online services}

In the new retail field combining online and offline, for consumers in physical stores, we can establish after-sales service system on the network platform under the condition that consumers can identify the products themselves, so as to meet consumers' demand for after-sales service for some products.For electricity customers, in the after-sales service system to be more pay attention to the return of goods services, at the same time in the commodity introduction interface ensure the information necessary to fully and real at the same time, as far as possible to high authenticity, word of mouth good recommendation to consumers, provide free trial service to the right goods at the same time, after check physical information with online commodity information for different situations provide free return rebate, eliminate false goods, to ensure that the store credit, build brand effect

\subsection{Build characteristic physical stores in supply chain sales [10-11]}

Why are brick-and-mortar stores in the United States, Japan and Europe not suffering from the same huge impact of e-commerce as In China?Because their traditional business and service model is quite perfect, to reach the height that Chinese bricks-and-mortar businesses cannot reach.Ecommerce can compress time, but it cannot make use of space. The core function of physical stores is the sense of space. The strategic advantage of physical stores is to give full play to their advantages in experience and interlace development of online retail, make full use of space, and bring consumers a sense of presence, participation and acquisition. The rapid development of China's Haidilao industry is the ultimate in the physical store service level.

\section{Conclusion}

Based on the analysis of the development background and market environment of the traditional retail industry, this paper summarizes the necessity and advantages of supply chain reform when the traditional retail enterprises transform to the new retail industry. Traditional retail enterprises should focus on the reform of the end of the supply chain, remove the criticism of the traditional retail model, and apply big data technology to supply chain sales. Traditional retail enterprises should pay attention to the distribution problem at the end of the supply chain and provide high-quality distribution services. In this way, traditional retail enterprises can complete the perfect transformation to the new retail industry by giving full play to the supply chain advantages of the new retail industry. 


\section{References}

[1] Luo Wen. RT-Mart reaches the net:RT-Mart cooperates with Tmall [J].Shanghai Business,2018.

[2] Wang Youxiang. Analysis on Inventory Cost Management Model of Retail Enterprises -- Taking WalMart as an example [J]. Guangxi Quality Supervision Herald,2021.

[3] Wu Yisi. The Popularity of membership retail: Four Secrets of Wal-mart Sam's Club [J]. Shopping Mall Modernization,2013.

[4] Mengxuan Wang. Analysis and Countermeasures of RT-MART Consumers' Consumption Behavior [J]. Modern Marketing (the next day),2018.

[5] Zuan Zhou. Research on new retail Transformation based on Big data -- A case study of Alibaba investment RT-Mart [J].Modern Business Trade Industry, 2020.

[6] Wu Kanghui. Research on the Combination of online and offline New retail [J]. Business News,2021.

[7] Ruonan Li. Based on new retail Research on RT-Mart Channel Innovation Strategy [J].E-Business Journal,2019.

[8] Ran Ma.Analysis of RT-Mart's Marketing Strategy [J].Market Modernlization,2015.

[9] Xuejia Zhang.Study on 020 Model of RT-Mart chain supermarket[J]. Market Modernization, 2015.

[10] Peng Fan. New retail -- Sounding the horn of the fourth retail revolution [M].Publishing House of Eletronics Industry,2018.

[11] David R. Ber.Location is Still Everything [M].Zhejiang People's Publishing House,2017. 